\title{
Döteron ile İndüklenmiş Uranyum İzotoplarının Tesir Kesiti Hesaplamaları
}

\author{
Deniz, CANBULA*
}

Manisa Celal Bayar Üniversitesi, Fen-Edebiyat Fakültesi, Fizik Bölümü, Manisa, Türkiye

\section{$\ddot{O} \mathbf{z}$}

Bu çalışmada, ${ }^{235} \mathrm{U}(\mathrm{d}, \mathrm{n}){ }^{238} \mathrm{~Np},{ }^{235} \mathrm{U}(\mathrm{d}, 2 \mathrm{n}){ }^{235} \mathrm{~Np},{ }^{235} \mathrm{U}(\mathrm{d}, 3 \mathrm{n}){ }^{234} \mathrm{~Np},{ }^{238} \mathrm{U}(\mathrm{d}, 2 \mathrm{n}){ }^{238} \mathrm{~Np}$ ve ${ }^{238} \mathrm{U}(\mathrm{d}, 4 \mathrm{n})^{236} \mathrm{~Np}$ reaksiyonlarının tesir kesitleri TALYS 1.6 bilgisayar programı kullanılarak 5$35 \mathrm{MeV}$ enerji aralığında hesaplanmıştır. Hesaplamalarda 3 tanesi mikroskopik (Skyrme HFB tabanlı seviye yoğunluğu modeli, Skyrme HFB tabanlı kombinasyonel seviye yoğunluğu modeli ve sıcaklığa bağlı Gogny HFB tabanlı seviye yoğunluğu modeli) 3 tanesi makroskopik (geri-kaydırılmış Fermi gaz modeli, sabit sıcaklık modeli, genelleştirilmiş süperakışkan model) seviye yoğunluğu modelleri opsiyonel birer girdi olarak kullanılmış ve reaksiyon tesir kesiti üzerindeki etkisi incelenmiştir. Teorik tahminler EXFOR veri tabanından alınan deneysel veriler ile karşılaştırılmıştır.

Anahtar Kelimeler: Nükleer seviye yoğunluğu, nükleer seviye yoğunluğu modelleri, TALYS, tesir kesiti.

\section{Cross Section Calculations of the Deuteron Induced Reactions on Uranium Isotopes}

\begin{abstract}
In this study, cross section of ${ }^{235} \mathrm{U}(\mathrm{d}, \mathrm{n}){ }^{238} \mathrm{~Np},{ }^{235} \mathrm{U}(\mathrm{d}, 2 \mathrm{n}){ }^{235} \mathrm{~Np},{ }^{235} \mathrm{U}(\mathrm{d}, 3 \mathrm{n}){ }^{234} \mathrm{~Np}$, ${ }^{238} \mathrm{U}(\mathrm{d}, 2 \mathrm{n}){ }^{238} \mathrm{~Np}$ and ${ }^{238} \mathrm{U}(\mathrm{d}, 4 \mathrm{n}){ }^{236} \mathrm{~Np}$ reactions are calculated by using TALYS 1.6 computer code in the energy range from 5 to $35 \mathrm{MeV}$. In the calculations, 3 microscopic (level density model based on Goriely Skyrme HFB, Hilaire combinatorial level density model based on Skyrme HFB, level density model based on temperature dependent Gogny HFB) 3 macroscopic (back-shifted Fermi gas model, constant temperature model, generalized superfluid model) level density models are used as an optional inputs and their effects on the reaction cross section are investigated. Theoretical predictions are compared with the experimental data taken from EXFOR library.

Keywords: Cross section, nuclear level density, nuclear level density models, TALYS.

\section{Giriş}

Uranyum önemli radyoaktif bir elementtir. Uranyum-238 (\%99.27), Uranyum-235 (\%0.72) ve Uranyum-234 $(\% 0.01)$ olmak üzere üç tane izotopu vardır. Uranyumun nükleer enerjideki önemi fark edilene kadar seramikte, fotoğrafçılıkta, kimyevi reaksiyonlarda katalizör olarak kullanılmıştır. Daha sonra uranyumun özellikle nükleer enerji santrallerinde yakıt olarak kullanılması ile yüksek enerji üretilmeye başlanmıştır.
\end{abstract}

\footnotetext{
${ }^{*}$ Sorumlu Yazar: ORCID ID: orcid.org/0000-0003-0283-2698 e-mail: denizcanbula@gmail.com
} 
Nükleer teknoloji alanında ileri seviyede gelişmiş ülkeler daha çok araştırma yapmak amaciyla uranyum izotoplarından yapay olarak neptünyum elde etmektedirler. Neptünyum izotopları doğada bulunmamaktadır. Ancak, uranyum izotoplarından gerçekleșen reaksiyonlar ile elde edilebilmektedir. Neptünyum-237 izotopunun yarılanma süresi 2.140.000 y1ldır ve bu yüzden nükleer sanayide kullanılmaktadır. Neptünyum-235 izotopunun yarılanma süresi 396 gündür ve çevresel uygulamalarda [1,2] iz bırakıcı olarak kullanılmaktadır. Neptünyum son derece toksik ve zararlı etkilere sahip olmasına rağmen nükleer yakıtların içerisinde az bir miktarda bulunması bile üretimi konusunda özellikle gelişmiş ülkeler açısından önem arz etmektedir. $\mathrm{Bu}$ bağlamda, uranyum izotoplarından döteron bombardımanı sonucunda neptünyum izotopu eldesi için ilk deney 1959 yılında Wing ve ark. [3] tarafindan 5.8-21.5 MeV enerji aralığında yapılmıştır. Bu çalışmada, Uranyum-235 ve Uranyum-238 izotoplarının döteron ve helyum iyonları ile bombardımanı sonucu elde edilen reaksiyonların tesir kesiti ölçümleri yapılmış ve bu ölçümler fisyon için modifiye edilmiş Jakson modeli [4] ile hesaplanan teorik tahminler ile karşılaştırılmıştır. Bunun yanı sıra, uranyum ve plütonyum gibi ağır çekirdeklerin 1şınım yakalama, parçacık yayınlama ve fisyon olaylarının tesir kesiti ölçümleri 5-25 MeV enerji aralığındaki döteron bombardımanı ile gerçekleştirilmiştir [5]. Bu ölçümde ağır hedef çekirdeklerin yüksek parçalanma ürün verimine yani kütle-etkisine sahip olduğu gözlenmiştir. Daha sonra 90'l1 yıllara gelindiğinde ilerleyen teknolojik imkanlar doğrultusunda uranyum hedef çekirdeklerinden neptünyum izotoplarının ayrılması süreçlerinin ölçümleri gerçekleştirilmiştir [6,7]. Ölçümlerde iki aşamalı yeni bir kimyasal metot kullanılmıştır. Yapılan bu deneysel ölçümlerin teorik analizleri de ilerleyen zamanlarda yapılmıştır $[8,9]$. Teorik tahminlerde hibrid model ve geometriye bağlı hibrid model opsiyonel birer girdi olarak alınmış ve hesaplamalarda ALİCE/ASH [10] bilgisayar kodu kullanılmıştır.

Döteronlar, parçalanma reaksiyonlarına kolayca dahil olabilen zayıf bağlı çekirdeklerdir. Bu yüzden, özellikle düşük enerjilerde (10 MeV altında) döteron 1şınlarının çok verimli bir şekilde nötronlar üretmek için kullanıldığı bilinmektedir. Elde edilen bu nötronlar geniş bir kullanım alanına (hibrid reaktör sistemleri) sahiptir. Ayrıca, döteron ile indüklenmiş 
reaksiyonlar da artık radyonüklidlerin üretimi, tıbbi radyoizotop üretimi, hızlandırıcı teknolojisi ve aktivasyon analizi için önemlidir. Döteron ile indüklenmiş nükleer reaksiyonların deneysel verilerini açıklamada farklı nükleer modeller kullanılan ve nükleer fizik literatürüne bu bağlamda önemli katkılar sağlayan çalışmalar mevcuttur $[11,12,13]$.

$\mathrm{Bu}$ çalışmada ise, Uranyum-235 ve Uranyum-238 izotoplarının döteron ile bombardımanı sonucunda neptünyum izotopu eldesi gerçekleştiren reaksiyonların tesir kesiti hesaplamaları yapılmıştır. Çalışmanın amacı, uranyum izotoplarının döteron bombardımanı sonucu oluşan nükleer reaksiyonlarının tesir kesitlerini açıklarken farklı nükleer seviye yoğunluğu modellerinin etkisini gösterebilmek ve bu tip reaksiyonlarda hangi enerji aralığında hangi modelin daha başarılı bir şekilde deneysel verileri açıkladığını sunabilmektir. Hesaplamalarda 3 tanesi mikroskopik (Skyrme HFB tabanlı seviye yoğunluğu modeli, Skyrme HFB tabanl kombinasyonel seviye yoğunluğu modeli ve sıcaklığa bağlı Gogny HFB tabanlı seviye yoğunluğu modeli) 3 tanesi makroskopik (geri-kaydırılmış Fermi gaz modeli, sabit sıcaklık modeli, genelleştirilmiş süperakışkan model) olmak üzere 6 farklı nükleer seviye yoğunluğu modeli opsiyonel birer girdi olarak kullanılarak tesir kesiti hesaplanmış ve nükleer seviye yoğunluğunun tesir kesiti üzerindeki etkisi incelenmiştir.

\section{Materyal ve Metot}

\section{Nükleer Seviye Yoğunluğu}

Sonsuz küçük bir enerji aralığında bulunan uyarılmış seviyelerin sayısı nükleer seviye yoğunluğu olarak tanımlanır. Nükleer seviye yoğunluğu astrofizik, medikal fizik, reaktör tasarımı gibi alanlarda oldukça önemli bir fonksiyon olmasının yanı sira reaksiyonların tesir kesiti hesaplamaları içinde çok önemli girdilerden bir tanesidir. Nükleer seviye yoğunluğu ile ilgili literatürde 3 adet mikroskopik (Skyrme HFB tabanlı seviye yoğunluğu modeli, Skyrme HFB tabanlı kombinasyonel seviye yoğunluğu modeli ve sıcaklığa bağlı Gogny HFB tabanlı seviye yoğunluğu modeli) 3 adet makroskopik (geri-kaydırılmış Fermi gaz modeli, sabit sıcaklık modeli, genelleştirilmiş süperakışkan model) model yer almaktadır. Bu üç makroskopik modelden en basit ve ilk olanı Fermi gaz modelidir [14]. Bu modele göre, nükleonlar birbirleri ile etkileşmezler, tek-parçacık enerji seviyelerine eşit boşluklar ile yerleşmişlerdir ve kollektif etkileri içermezler. $\mathrm{Bu}$ bilgiler 
doğrultusunda, uyarılma enerjisine bağl1 toplam seviye yoğunluğu fonksiyonu

$$
\rho^{t o p}(U)=\frac{1}{12 \sqrt{2} \sigma} \frac{\exp [2 \sqrt{a U}]}{a^{1 / 4} U^{5 / 4}}
$$

şeklinde verilir. Burada $U$ uyarılma enerjisi, $a$ seviye yoğunluğu fonksiyonunun temel değişkeni olan seviye yoğunluğu parametresi, $\sigma^{2}$ spin eşik parametresidir. Yüksek enerjilerde Fermi gaz ifadesinin uyarılma enerjisi $E$ etkin uyarılma enerjisi olmak üzere $U=E-\Delta$ biçiminde bir kayma parametresi içermektedir. $\mathrm{Bu}$ duruma geri-kaydırılmış Fermi gaz modeli (BSFGM) denir. Diğer bir makroskopik model ise sabit sıcaklık modelidir (CTM) [15]. Bu model bir eşleşme enerjisi öngörür. $0 \mathrm{MeV}$ den bu eşleşme enerjisine kadar olan bölgede sabit sıcaklık kurallarının uygulandığ 1 , eşleşme enerjisinden sonraki bölgede Fermi gaz modelinin geçerli olduğu iki kısım şeklinde ele alınır. Son makroskopik model olan genelleştirilmiş süperakışkan model (GSM), BCS (Bardeen-Cooper-Schiffer) $[16,17]$ teorisine dayanmaktadır. $\mathrm{Bu}$ teori süperiletken çiftlenme korelasyonlarını hesaba katar. $\mathrm{Bu}$ etkinin nükleer seviye yoğunluğu fonksiyonu üzerinde kuvvetli bir etkisinin olduğunu, düşük enerjideki süperakışkan davranıştan Fermi gaz modeli ile tanımlanan yüksek enerji bölgesine geçişi bir faz geçişi ile karakterize ederek göstermiștir. Daha kompleks sistemler, özellikle nükleer astrofizikteki spesifik uygulamalar için deneysel olarak bilinen bölgeden daha geniş bölgelere geçiş yapılmak istendiği zaman güvenilir istatistiksel temellere dayandırılmış mikroskopik veya yarı-mikroskopik modellere ihtiyaç duyulur. $\mathrm{Bu}$ yüzden mikroskopik modellerin daha iyi sonuçlar vereceği tahmin edilirken, bu modellerin daha zaman alıcı ve uzun sürmesi ve makroskopik modellere nazaran daha zor hesap süreçlerine sahip olmalarından dolayı makroskopik modellerin mikroskopik modellere yakın başarı elde ettikleri durumlarda, makroskopik modeller daha çok tercih edilebilir olmaktadır. Mikroskopik modellerden birisi Skyrme HFB tabanlı seviye yoğunluğu modelidir [18]. Goriely ve arkadaşları tarafından 150 $\mathrm{MeV}$ uyarılma enerjisine ve $I=30$ spin değerine kadar Hartre - Fock - Bogolyubov (HFB) hesaplamalarını temel alarak nükleer seviye yoğunluklarını hesaplamıştır. Diğer bir mikroskopik model ise, Skyrme HFB tabanlı kombinasyonel seviye yoğunluğu modelidir [19]. Kombinasyonel model, enerji, spin, parite bağımlılığını içermesi yanında esas durum yoğunluğunu ve kollektif artışında detaylı mikroskopik hesabını içermektedir. Bu model ile nükleer seviye yoğunluğu değeri 8500 'den fazla 
çekirdek için $200 \mathrm{MeV}$ uyarılma enerjisi ve $I=49$ spin değerine kadar hesaplanmış ve tablolanmıştır. Sonuncu ve en gelişmiş mikroskopik model ise, sicaklığa bağlı Gogny HFB tabanlı seviye yoğunluğu modelidir [20]. Hartree-Fock BCS tabanlı istatistiksel yaklaşım içeren mikroskopik modeller ile deneysel verileri tekrar elde etmede ve nükleer uygulamalarda düşük enerjilerde de makroskopik modellere yakın bir başarı gösterildiği ortaya konmuştur.

\section{Talys 1.6 Bilgisayar Programı}

Nükleer reaksiyonların tesir kesiti hesaplamalarında en iyi bilinen bilgisayar programlarından bir tanesi TALYS dir [21]. $\mathrm{Bu}$ bilgisayar programı $1 \mathrm{keV}-1 \mathrm{GeV}$ enerji aralığında alfa, triton, döteron, proton, nötron, gama 1şını gibi parçacıkların oluşturduğu nükleer reaksiyonları simüle eden bir programdir. $\mathrm{Bu}$ programda farklı nükleer seviye yoğunluğu modelleri opsiyonel girdi olarak kullanılabilir.

\section{Araştırma Bulguları}

$\mathrm{Bu} \quad$ çalışmada, $\quad{ }^{235} \mathrm{U}(\mathrm{d}, \mathrm{n}){ }^{238} \mathrm{~Np}$, ${ }^{235} \mathrm{U}(\mathrm{d}, 2 \mathrm{n}){ }^{235} \mathrm{~Np}, \quad{ }^{235} \mathrm{U}(\mathrm{d}, 3 \mathrm{n}){ }^{234} \mathrm{~Np}$, ${ }^{238} \mathrm{U}(\mathrm{d}, 2 \mathrm{n}){ }^{238} \mathrm{~Np} \quad$ ve $\quad{ }^{238} \mathrm{U}(\mathrm{d}, 4 \mathrm{n}){ }^{236} \mathrm{~Np}$ reaksiyonlarının tesir kesiti hesaplamalarını gerçekleştirebilmek için TALYS 1.6 bilgisayar programı kullanılmış ve hesaplamalar 5-35 MeV enerji aralığında yapılmıştır. Hesaplamalarda 3 tanesi mikroskopik ve 3 tanesi makroskopik olmak üzere 6 farklı nükleer seviye yoğunluğu modeli seçilmiş ve nükleer seviye yoğunluğunun tesir kesitleri üzerindeki etkisi incelenmiştir. Elde edilen teorik tahminler reaksiyonlara ait deneysel veriler ve birbirleri ile karşılaştırılarak modeller ile ilgili tespitler yapılmıştır.

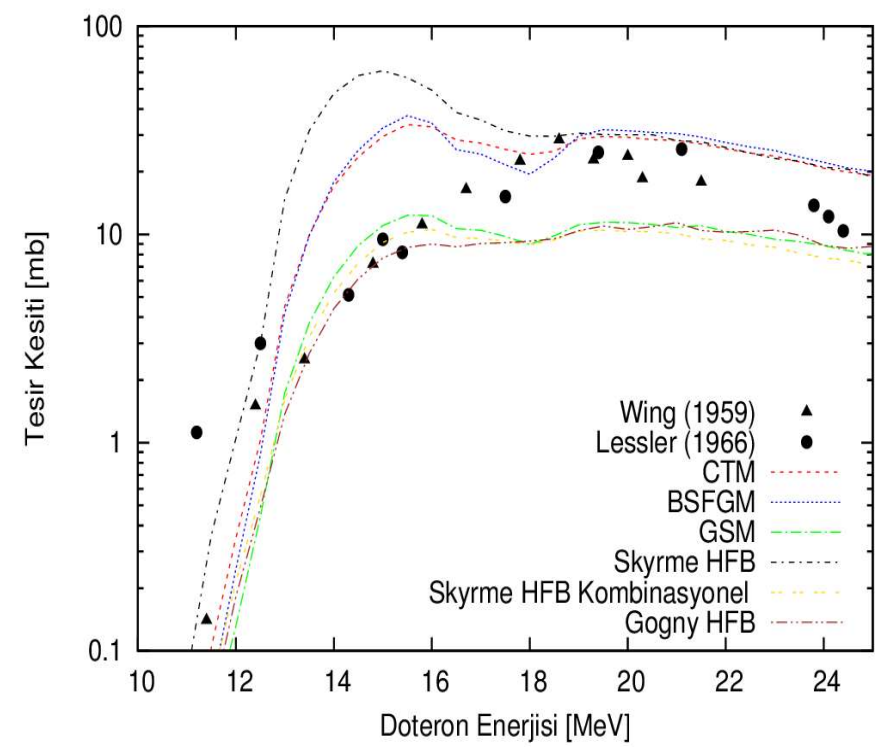

Şekil 1. (Renkli) ${ }^{235} U(d, 3 n){ }^{234} \mathrm{~Np}$ reaksiyonun tesir kesiti hesaplamalart ve deneysel veriler [3,5] ile karşılaş̧tırması.

${ }^{235} \mathrm{U}(\mathrm{d}, 3 \mathrm{n}){ }^{234} \mathrm{~Np}$ reaksiyonun tesir kesiti tahminleri ve onların deneysel veriler [3,5] ile karşılaştırılması Şekil 1'de görülmektedir. Şekil incelendiğinde, düşük enerjilerde makroskopik modeller deneysel verileri sağlamakta başarılı sonuçlar verirken artan döteron enerjilerinde deneysel verilere en yakın uyumu mikroskopik modeller göstermektedir. Özellikle GSM'nin düşük enerjilerde 
deneysel verileri sağlamada başarı göstermesi reaksiyondaki nötron çiftlenmesinden dolayı bu modelin temelinde beklenen bir başarıdır. Yüksek enerjilerde hatta tüm enerji bölgesinde mikroskopik modellerin başarılı olması beklenen bir durumken düşük enerjilerde makroskopik bir modelin bu açığ 1 kapatması göz önünde bulundurulmalıdır.

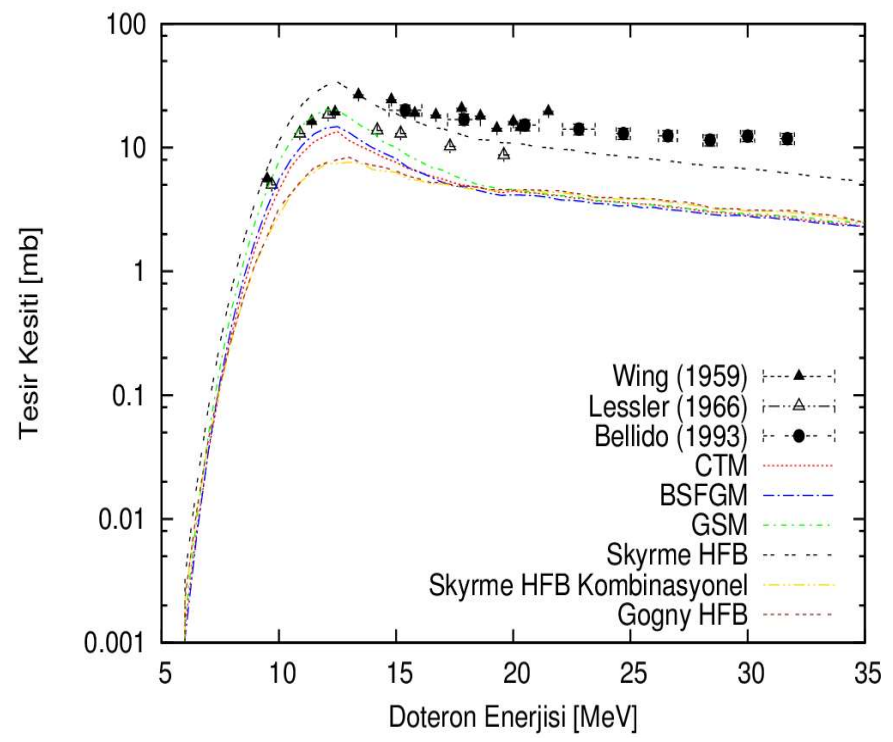

Şekil 2. (Renkli) ${ }^{235} U(d, 2 n)^{235} N$ p reaksiyonun tesir kesiti hesaplamalarl ve deneysel veriler [3,5,6] ile karşılaştırması.

$$
\text { Şekil 2'de, } \quad{ }^{235} \mathrm{U}(\mathrm{d}, 2 \mathrm{n})^{235} \mathrm{~Np}
$$
reaksiyonun tesir kesiti tahminlerinde 6 farklı nükleer seviye yoğunluğu modelinin reaksiyona ait deneysel ölçümler $[3,5,6]$ ile karşılaştırması görülmektedir. Burada yine Şekil 1 deki sonuca benzer bir durum söz konusudur. Düşük enerjilerde GSM modeli çiftlenme etkilerinden dolayı verileri sağlamada başarılı olurken artan enerjilerde mikroskopik bir model bu açığı kapatarak verilere en yakın uyumu sergilemektedir.

$$
{ }^{235} \mathrm{U}(\mathrm{d}, \mathrm{n}){ }^{236} \mathrm{~Np} \text { reaksiyonun tesir }
$$

kesiti hesaplama sonuçlarının deneysel veriler ile karşılaştırılması Şekil 3 ile verilmiştir. $\mathrm{Bu}$ reaksiyonda tek nötron üretimi gerçekleştiği ve çiftlenme olmadığı için özellikle GSM deneysel veriler ile oldukça uyumsuz sonuçlar elde edilmesine neden olmuştur.

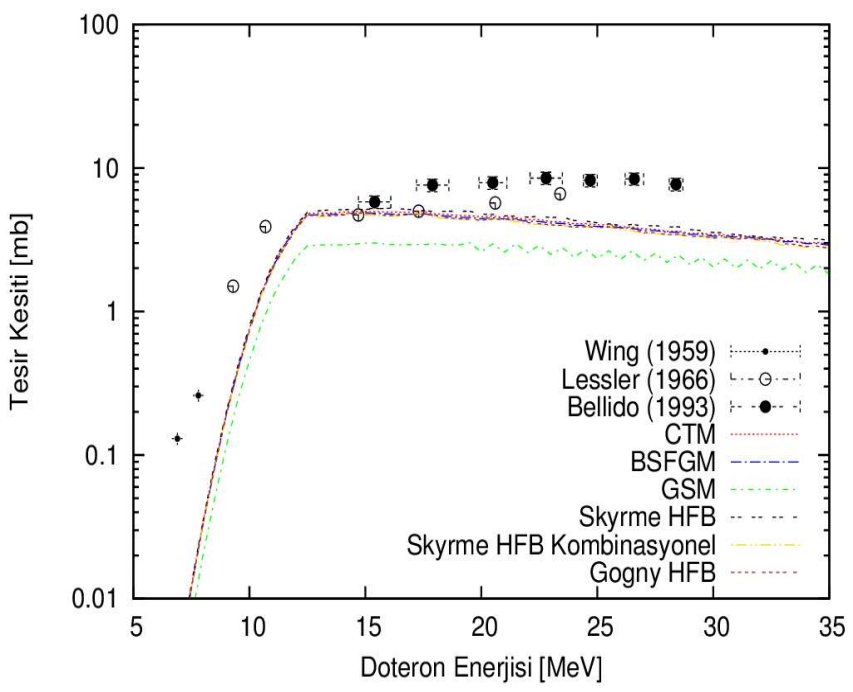

Şekil 3. (Renkli) ${ }^{235} U(d, n){ }^{236} N p$ reaksiyonun tesir kesiti hesaplamalarl ve deneysel veriler [3,5,6] ile karşılaştırmast.

$\mathrm{Bu}$ durumdan dolayı diğer mikroskopik ve makroskopik modeller ise birbirlerine yakın sonuçlar sergilemişlerdir. Modeller arasında çiftlenme haricinde bir durumdan kaynaklanan belirgin bir ayrım söz konusu değildir.

Şekil 4'de, $\quad{ }^{238} \mathrm{U}(\mathrm{d}, 2 \mathrm{n}){ }^{238} \mathrm{~Np}$ reaksiyonun tesir kesiti tahminlerinin 
deneysel veriler $[3,5,7]$ ile karşılaştırması görülmektedir. Bu şekilde GSM-BSFGMCTM ve Skyrme HFB deneysel verileri sağlamada benzer başarıyı yakalamışlardır. Burada, tüm enerji bölgesi için mikroskopik bir modelin deneysel veriler ile sağladığı uyumun makroskopik modeller ile yakalanması yorumu yapılabilir. Çünkü, mikroskopik modellerin hesaplamalarının çok daha fazla zaman alması ve zor bir süreç olduğu göz önüne alınırsa, makroskopik bir modelin alternatif bir seçenek olması tercih edilebilir bir durumdur. Ancak, reaksiyonun gerçekleştiği enerji aralığı da göz $\operatorname{ard} 1$ edilmemelidir. Özellikle düşük enerjilerde makroskopik modellerin deneysel verileri sağlamada başarılı olduğu ve bu durumun bizim hesaplamalarımızda da açıkça görüldüğü söylenebilir.

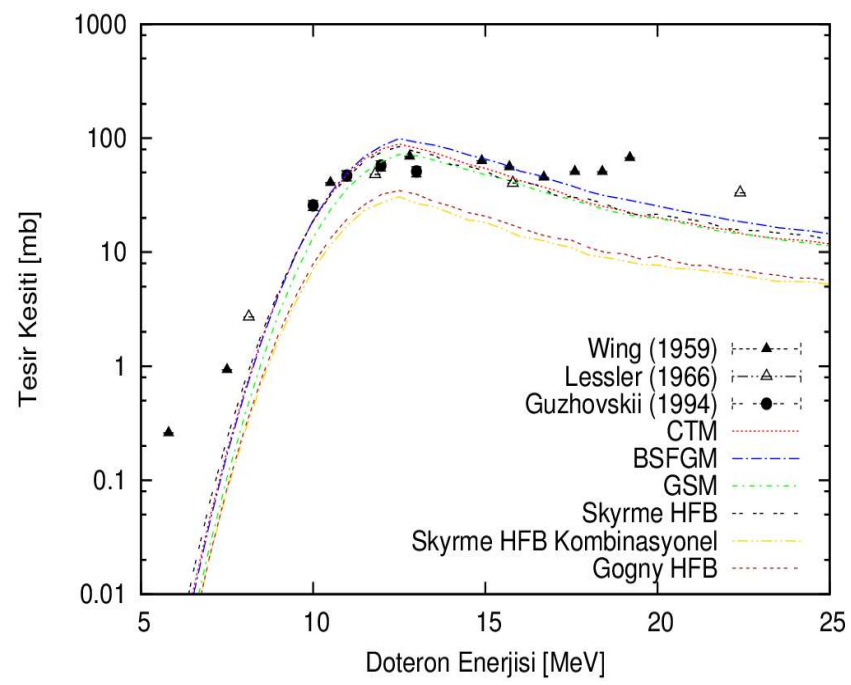

Şekil 4. (Renkli) ${ }^{238} U(d, 2 n)^{238} \mathrm{~Np}$ reaksiyonun tesir kesiti hesaplamalarl ve deneysel veriler [3,5,7] ile karşılaş̧tırmast.
Şekil 5 incelendiğinde, ${ }^{238} \mathrm{U}(\mathrm{d}, 4 \mathrm{n}){ }^{236} \mathrm{~Np}$ reaksiyonun tesir kesiti tahminlerinin deneysel veriler $[3,5,6]$ ile karşılaştırılması görülmektedir. $\mathrm{Bu}$ reaksiyonun diğer reaksiyonlara nazaran daha yüksek eşik enerjisine sahip olmasından dolayı makroskopik modeller deneysel verileri sağlamada başarısız olmuşlardır. Deneysel verilere en yakın sonucu Skyrme HFB kombinasyonel model sağlamaktadır. Kombinasyonel mikroskopik modeller nükleer seviye yoğunluğunun enerji, spin, parite bağımlılığının yanı sıra sadece istatistiksel olarak elde edilebilen kısmi parçacıkboşluğu (ph) seviye yoğunluğunu da elde etmeye imkan sağlar. Bundan dolayı, bazı reaksiyonlarda deneysel verilerin tekrar üretilmesinde daha başarılıdırlar.

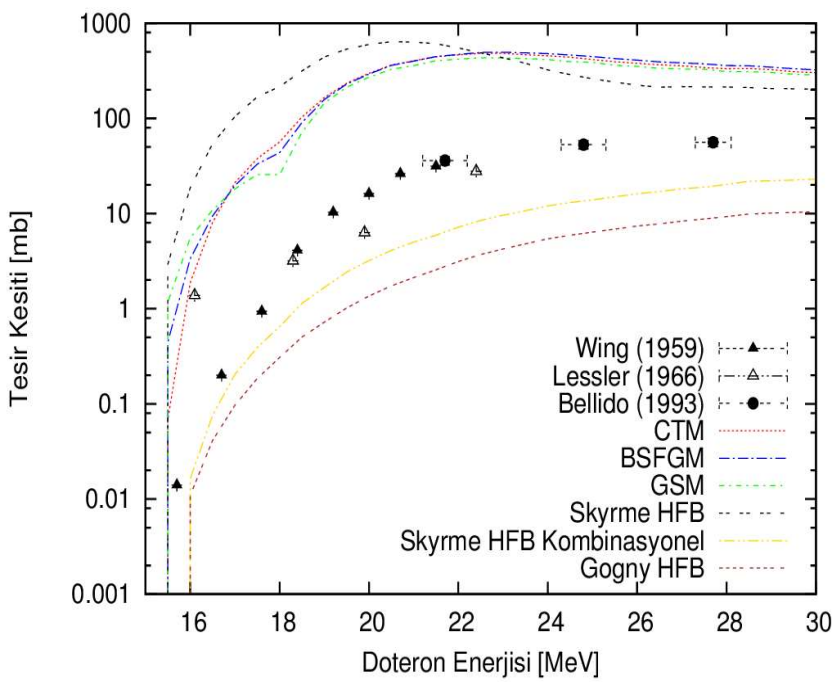

Şekil 5. (Renkli) ${ }^{238} U(d, 4 n){ }^{236} N p$ reaksiyonun tesir kesiti hesaplamalart ve deneysel veriler [3,5,6] ile karşılaştırması. 


\section{Sonuc}

${ }^{235} \mathrm{U}$ ve ${ }^{238} \mathrm{U}$ izotoplarının döteron ile indüklenmesi sonucu oluşan reaksiyonların tesir kesitleri hesaplanmış ve sonuçlar bu reaksiyonların deneysel verileri ile karşılaştırılmıştır. Bir önceki bölümde yapılan değerlendirmeler 1şı̆̆ında şu tespitler yapılabilir:

- Uranyum-235 izotopunun hedef çekirdek olduğu reaksiyonlarda, özellikle düşük reaksiyon enerjilerinde çiftlenme korelasyonlarının nükleer seviye yoğunluğu üzerinde kuvvetli bir şekilde etkisinin olduğu Şekil 1 ve 2 deki hesaplarda açıkça görülmektedir.

- Makroskopik modellerin düşük enerjilerdeki başarısı göz ardı edilemezken artan enerjilerde mikroskopik modellerin gerekliliğinin göz ardı edilemez olduğu sunulmuştur.

- Döteron ile indüklenmiş nükleer reaksiyon çalışmalarının tesir kesiti hesaplamalarında düşük enerjilerde makroskopik modellerin, yüksek enerjilerde mikroskopik modellerin deneysel verileri açıklamadaki başarısı sunularak bu modellerin bu enerji aralıklarında güvenle kullanılabilecek birer araç olduğu belirtilmiştir.

- Genel olarak tüm sonuçlara bakıldığında nükleer seviye yoğunluğu fonksiyonun hesaplara dahil edilerek tesir kesitlerinin hesaplanması deneysel veriler ile uyumlu sonuçlara ulaşılmasına neden olmuştur. Uranyum izotoplarının döteron ile indüklenmesi sonucu oluşan reaksiyonların tesir kesiti hesaplamalarında seviye yoğunluğunun belirgin bir yeri olduğu söylenebilir.

\section{Kaynaklar}

[1] Harvey BR, Sutton GA, 1987. The properties of $235 \mathrm{~Np}$ as a tracer and yield monitor in studies of the environmental behaviour of neptunium. Nuclear Instruments and Methods A, 254: 172-181.

[2] Morello M, Colle C, Bernard J, 1986. Less Common Methods, 122: 569.

[3] Wing J ve arkadaşları, 1959. Excitation functions of $U 235$ and $U 238$ bombarded with helium and deuterium ions. Physical Review 114: 163-173.

[4] Jackson JD, 1956. Canadian Journal of Physics, 34:767.

[5] Lessler RM, Gibson VM, Glass RA, 1966. Radiative capture, particle emission and fission in heavy nuclei. Nuclear Physics, 81: 401.

[6] Bellido LF, Rabinson VJ, Sims HE, 1993. Excitation functions for the U235,238(d, xn)Np-237,240 reactions. Radiochimica Acta, 62: 123.

[7] Guzhovskii BY ve arkadaşları,1994. Cross-section activation measurement for $\mathrm{U}-238$ through protons and deuterons in energy interval 10-14 MeV. International Conference of Nuclear Data Science and Technical, Gatlinburg, 390. 
[8] Büyükuslu H ve arkadaşları, 2010. Theoretical cross sections of ${ }^{209} \mathrm{Bi},{ }^{232} \mathrm{Th}$, ${ }^{235} \mathrm{U}$ and ${ }^{238} \mathrm{U}$ on deuteron-induced reactions. Annals and Nuclear Energy, 37: 534-539.

[9] Kaplan A ve arkadaşları, 2010. Excitation functions of some neutron production targets on $(\mathrm{d}, 2 \mathrm{n})$ reactions. Journal of Fusion Energy, 29: 181-187.

[10] Broeders CHM, Konobeyev AY, Korovin YA, Lunev VP, Blann M, 2006. Pre-compound and evaporation model code system for calculation of excitation functions energy and angular distributions of emitted particles in nuclear reactions at intermediate energies. ALICE/ASH FZK 7183 http://bibliothek.fzk.de/zb/berichte/FZKA7 183.pdf

[11] Yiğit M, Tel E, 2014. Nuclear model calculation for production of $18 \mathrm{~F}, 22 \mathrm{Na}, 44$, $46 \mathrm{Sc}, 54 \mathrm{Mn}, 64 \mathrm{Cu}, 68 \mathrm{Ga}, 76 \mathrm{Br}$ and $90 \mathrm{Y}$ radionuclides used in medical applications. Annals of Nuclear Energy, 69: 44-50.

[12] Yiğit M, Tel E, Kara A, 2013. Deuteron Induced (d, p) and (d, 2p) Nuclear Reactions up to $50 \mathrm{MeV}$. Journal Of Fusion Energy, 32(3): 362-370.

[13] Yiğit M, Tel E, 2017. Theoretical determination of $(d, n)$ and $(d, 2 n)$ excitation functions of some structural fusion materials irradiated by deuterons. Nuclear Science and Techniques, 28(11): 165.

[14] Bethe HA, 1937. Nuclear Physics B. Nuclear Dynamics, Theoretical. Review of Modern Physics, 9: 69.
[15] Gilbert A, Cameron AG, 1965. A composite nuclear level density formula with shell corrections. Canadian Journal of Physics, 43(8): 1446-1496.

[16] Ignatyuk AV, Istekov KK, Smirenkin GN, 1979. Role of collective effects in systematics of level density of nuclei (No.KFK-TR--632).

Kernforschungszentrum Karlsruhe $\mathrm{GmbH}$ Germany.

[17] Ignatyuk AV, Weil JL, Raman S, Kahane S, 1993. Density of discrete levels in Sn 116. Physical Review C, 47(4): 1504.

[18] Goriely S, Tondeur F, Pearson JM, 2001. Atomic Data Nuclear Data Tables, 77: 311

[19] Goriely S, Hilaire S, Koning AJ, 2008. Improvedmicroscopic nuclear level densities within the HFB pluscombinatorial method. Physical Review C, 78: 064307.

[20] Hilaire S, Girod M, Goriely S, Koning A, 2012. Temperature dependent combinatorial level densitieswith the D1M Gogny force. Physical Review C, 86: 064317.

[21] Koning AJ, Hilaire S, Duijvestijn M, 2008. C.TALYS-1.0. EDP Sciences, 211214. 